\section{BMJ Global Health}

cite: Kay A, Leidman $E$ Lopez V, et al. The burden of anaemia among displaced women and children in refugee settings worldwide, 2013-2016. BMJ Global Health 2019;4:e001837. doi:10.1136/ bmjgh-2019-001837

Handling editor Seye Abimbola

- Additional material is published online only. To view please visit the journal online (http://dx.doi.org/10.1136/ bmjgh-2019-001837).

Received 12 July 2019 Revised 29 August 2019 Accepted 22 September 2019

Check for updates

(c) Author(s) (or their employer(s)) 2019. Re-use permitted under CC BY-NC. No commercial re-use. See rights and permissions. Published by BMJ.

${ }^{1}$ Emory University Rollins School of Public Health, Atlanta, Georgia, USA

${ }^{2}$ Center for Global Health, Centers for Disease Control and Prevention, Atlanta, Georgia, USA

${ }^{3}$ Division of Programme Support and Management, Public Health Section, United Nations High Commissioner for Refugees, Geneva, Switzerland

Correspondence to

Ms Eva Leidman;

eleidman@cdc.gov

\title{
The burden of anaemia among displaced women and children in refugee settings worldwide, 2013-2016
}

\author{
Ariel Kay, ${ }^{1}$ Eva Leidman (D , ${ }^{2}$ Velma Lopez, ${ }^{2}$ Caroline Wilkinson, ${ }^{3}$ Melody Tondeur, ${ }^{3}$ \\ Oleg Bilukha ${ }^{2}$
}

\section{ABSTRACT}

Introduction Displaced persons have a unique risk for developing anaemia due to often limited diets, overcrowding, new infections and inadequate sanitation and hygiene. The lack of anaemia prevalence estimates among the displaced inhibit global planning for anaemia reduction.

Methods We analysed population representative, crosssectional nutrition surveys from 2013 to 2016 conducted by the United Nations High Commissioner for Refugees and partner agencies. Included surveys measured haemoglobin concentration among children 6-59 months, non-pregnant women 15-49 years, or both groups. For each survey, we calculated mean haemoglobin and prevalence of total anaemia ( $<110 \mathrm{~g} / \mathrm{L}$ in children, $<120 \mathrm{~g} / \mathrm{L}$ in women), and classified public health severity following WHO guidelines. Pearson correlations between indicators from women and children surveys were calculated where both subpopulations were measured.

Results Analysis included 196 surveys among children and 184 surveys among women from 121 unique refugee settings in 24 countries. The median prevalence of total anaemia in children and women was $44 \%$ and $28 \%$, respectively. Sixty-one per cent of child surveys indicated a problem of severe public health importance compared with $25 \%$ of surveys in women. The prevalence of total anaemia in children and women was strongly correlated $(\rho=0.80)$. Median prevalence of total anaemia was approximately $55 \%$ greater and mean haemoglobin was $6 \mathrm{~g} / \mathrm{L}$ lower among children age 6-23 months compared with children 24-59 months. West and Central Africa region had the highest median prevalence of anaemia both in women and children.

Conclusion While the burden of anaemia is high among the displaced, it mirrors that of the general population. Haemoglobin should continue to be measured in nutrition surveys in refugee settings. Sustained, multisectoral efforts to reduce anaemia are needed, with specific focus on children under 2 years of age and refugee settings in the West and Central Africa region.

\section{BACKGROUND}

Anaemia is prevalent among women and children throughout the world. Globally, approximately $43 \%$ of children, $29 \%$ of

\section{Key questions}

What is already known?

- Anaemia and low haemoglobin are important risk factors for health and nutritional status among women and children.

- Global and regional anaemia prevalence have been reported by various sources, including the Global Burden of Disease Study and the Nutrition Impact Model Study Group (Anaemia).

- Global estimates among refugees have not been previously published.

What are the new findings?

- Anaemia was a problem of severe public health significance in more than half of surveys among children 6-59 months and in approximately a quarter of surveys of non-pregnant women aged 15-49 years.

- While the anaemia prevalence estimated among the displaced were high, the burden and regional patterns mirror that of the general population.

What do the new findings imply?

- The presented data provide the first consolidated report of anaemia among displaced persons allowing for improved global comparisons and monitoring.

- The findings of sustained, high levels of anaemia suggest a need for continued multisectoral efforts to reduce anaemia, with specific focus on children under 2 years of age and refugee settings in the West and Central Africa region.

non-pregnant women and $38 \%$ of pregnant women are estimated to be anaemic. ${ }^{1}$ The aetiology of anaemia is complex, resulting from infections, inherited blood disorders, non-communicable diseases and nutritional deficiencies, with the relative contribution of each highly varied across settings. ${ }^{2-4}$ Iron deficiency anaemia (IDA), the major cause of anaemia in many countries, has been linked with poorer motor, ${ }^{5}$ social-emotional,${ }^{67}$ and cognitive function ${ }^{8}$ in infancy, in addition to neurophysiologic differences later in life. ${ }^{9}$ IDA among pregnant women has been associated with increased risk of maternal and 
perinatal mortality, ${ }^{10-12}$ as well as low birth weight of children. ${ }^{13} 14$ These poor health outcomes exist as part of a larger dynamic ecosystem in which the social, economic and political context drive malnutrition ${ }^{15}$ through routes of poverty, ${ }^{1617}$ exposure to pathogens ${ }^{1819}$ and inadequate or poor quality diet. ${ }^{17}$

As previous studies have documented, refugees and displaced persons have a unique risk for nutrient deficiencies; overcrowded living spaces, inconsistent access to clean water, safe sanitation, and adequate hygiene, and heightened exposure to infectious diseases all exacerbate risk. ${ }^{20-22}$ Importantly, diet patterns among the displaced play an important role in propagating malnutrition. Caloric intake is often primarily from non-perishable core commodities that can result in limited micronutrient intake. ${ }^{23}{ }^{24}$ Traditionally, fortified staple foods have been provided to those living in refugee settings in the form of food assistance. ${ }^{25}$ Dependency on food assistance to supplement nutritional needs, however, may further increase the risk of micronutrient deficiencies, principally among those living in long-term camp settings. ${ }^{26-28}$ Furthermore, evidence suggests that anaemia may be a public health concern among the displaced even where the prevalence of acute malnutrition does not reach thresholds for alarm. ${ }^{29}$

Despite the public health importance of anaemia in displaced populations and current programmes designed to address this problem, global estimates of anaemia among individuals living in refugee settings are limited. To address this information gap, the 2008 United Nations High Commissioner for Refugees (UNHCR) Anaemia Strategy prioritised standardisation of population-level anaemia estimation. ${ }^{30} \mathrm{~A}$ decade later, surveys including haemoglobin measurements have been completed in a majority of refugee settings supported by the agency. Our aim, therefore, was to assess global patterns in anaemia among children 6-59 months and non-pregnant women of reproductive age living in refugee settings between 2013 and 2016. Measuring the burden of anaemia among these populations is a preliminary step towards formulating programmatic directions for the nutrition and public health sectors.

\section{METHODS}

\section{Data source}

Data were obtained from population representative, cross-sectional surveys conducted in refugee camps or among refugees living in host communities between 2013 and 2016 by UNHCR and its partner agencies. Survey design and implementation reflected the UNHCR Standardised Expanded Nutrition Surveys (SENS) guidelines, ${ }^{31-33}$ a standardised methodology to conduct periodic nutrition surveys in refugee settings, and are based on Standardised Monitoring and Assessment of Relief and Transitions methods. ${ }^{34}$ Surveys applied cluster sampling, simple random sampling, systematic random sampling, or exhaustive sampling design depending on the type of setting, population size and availability and quality of household lists. Cluster surveys were conducted using a two-stage cluster sampling design: the first stage used probability-proportional-to-size to select clusters, followed by a random selection of households. ${ }^{31} 33$

SENS surveys are used to monitor the nutritional and health status of displaced populations. Standard survey modules-Anthropometry and Health, Anaemia, Infant and Young Child Feeding Practices, Food Security, Water and Sanitation and Hygiene and Mosquito Net Coverage-were included or excluded by setting based on priority data needs and existing or planned public health interventions. Our analysis used surveys that included haemoglobin concentration measurement from children aged 6-59 months and/or non-pregnant women aged $15-49$ years.

SENS guidelines recommend different household sampling strategies for anaemia measurement based on a setting's implemented or planned nutritional interventions. Either all households, or half of the households, included in the survey were randomly selected for haemoglobin measurement. ${ }^{31} 33$ Once a household was selected, haemoglobin testing was conducted on all eligible children and/or women. Haemoglobin concentration was measured using a capillary blood sample from the fingertip and recorded in grams per decilitre $(\mathrm{g} / \mathrm{dL})$ or grams per litre $(\mathrm{g} / \mathrm{L})$ using the HemoCue $\mathrm{Hb} 301$ Analyser. ${ }^{31} 3235$ Functioning of the HemoCue machines (photometer and microcuvette) were evaluated prior to the start of data collection and at the midpoint of data collection using liquid control solutions (Eurotrol $\mathrm{Hb}$ 301 Control)

Surveys were conducted by separate teams of local enumerators in each setting. Interviews were conducted in the local language of the refugees. Enumerators were trained for an average of 5 days. Prior to data collection in each setting, a pilot test was conducted. Teams were supervised during data collection by UNHCR nutrition staff as well as supervisors from partner agencies or local governments in select settings. In most settings, data were collected on mobile phones using Open Data Kit software.

\section{Data analysis}

Haemoglobin measures were adjusted in accordance with the $2001 \mathrm{WHO}$ guidelines in settings at an altitude greater than 1000 metres above sea level. ${ }^{36} 37$ Adjustments for smoking and inflammation were not performed as these data were not collected. Haemoglobin concentrations were categorised according to WHO recommended cutoff values to calculate the prevalence of anaemia. Among children aged 6-59 months, anaemia was classified as total $(<110 \mathrm{~g} / \mathrm{L})$, mild $(100-109 \mathrm{~g} / \mathrm{L})$, moderate (70-99 $\mathrm{g} / \mathrm{L})$ and severe $(<70 \mathrm{~g} / \mathrm{L}) .{ }^{36}{ }^{38}$ Among non-pregnant women aged 15-49 years, anaemia was classified as total $(<120 \mathrm{~g} / \mathrm{L})$, mild (110-119 g/L), moderate (80-109 $\mathrm{g} / \mathrm{L})$ and severe $(<80 \mathrm{~g} / \mathrm{L}){ }^{36}{ }^{38}$ Haemoglobin values in children or women greater than $180 \mathrm{~g} / \mathrm{dL}$ or less than 40 
$\mathrm{g} / \mathrm{dL}$ were excluded from analysis. ${ }^{39}$ Due to the low prevalence of severe anaemia among children and women, a 'moderate+severe classification' was created and defined as haemoglobin measures below $100 \mathrm{~g} / \mathrm{L}$ for children, and below $110 \mathrm{~g} / \mathrm{L}$ for women. For both women and children, we excluded surveys missing haemoglobin measures for $70 \%$ or more of eligible participants.

Surveys were classified according to whether data were collected in children only, women only, or in both children and women. For each survey, mean haemoglobin and prevalence of total, mild, moderate, severe and moderate+severe anaemia were calculated for children and women. The median and IQR were calculated for survey-level mean haemoglobin and anaemia prevalence. Additionally, surveys were classified as having a problem of severe public health importance if total anaemia prevalence was $\geq 40 \%$, based on $2000 \mathrm{WHO}$ guidelines. ${ }^{38}$ Estimates by six geographic regions and survey year were also calculated. Ethiopia and Chad were classified geographically as their own categories due to the large number of surveys conducted in each country.

One objective of our analysis was to describe the haemoglobin concentration and prevalence of anaemia for children and women residing in UNHCR refugee settings. We did this in three ways. First, we performed analyses that included all surveys. Second, since many settings had more than one survey conducted during the study period, we repeated analyses to present only one estimate for each anaemia indicator per setting. In the settings with more than one survey during the study period, we calculated the median value by setting for each anaemia indicator. Finally, we repeated this analysis using the estimate for each anaemia indicator from the most recent survey in each setting instead of the median value. There was little difference between the two methods of analyses (online supplementary files 1-3).

In the subset of surveys where haemoglobin measurements were conducted among both children and women, Pearson correlations between anaemia indicators in these populations were calculated. Region-specific correlations were calculated for all regions except South Asia due to the small number of settings where the survey measured anaemia in both women and children $(n=4)$; however, South Asia surveys conducted in both women and children were included in overall correlation analyses.

All data aggregation, cleaning and analyses were performed using SAS software V.9.3 and V.9.4. ${ }^{40} 41$ All figures were produced in RStudio V.1.1.463, using the reshape 2 and ggplot2 packages. ${ }^{42-44}$

The Internal Review Board of the Centres for Disease Control and Prevention reviewed the study protocol and determined it to be non-research secondary analysis of routinely collected programmatic data. No individual identifiers were included in the datasets used for this analysis.

\section{Patient and public involvement}

Patients were not involved in this study.

\section{RESULTS}

Two hundred and twenty-five surveys conducted during 2013-2016 among children were available for analysis, of which 196 of them measured haemoglobin and were therefore included in the study. For non-pregnant women, there were 195 surveys available and 184 surveys were included in this study. Of those, 165 surveys collected data on both women and children (online supplementary file 4). Overall, 81 (41.3\%) surveys assessing children and $80(43.5 \%)$ surveys assessing women used a cluster sampling design. From the included surveys, 96/92 $560(0.1 \%)$ children and 21/44 $519(0.05 \%)$ women were determined to have biologically implausible values and excluded. The proportion of values excluded and missing due to study design, absence or refusal by survey are presented in online supplementary files 5 and 6 .

Surveys were conducted in refugee settings located in 24 countries. Ethiopia and Chad had the largest number of surveys conducted (50 surveys for children and 37 surveys for women in Ethiopia, 38 surveys for children and 42 surveys for women in Chad). In all other countries, the total number of surveys conducted ranged from one to 18 surveys. The region with the greatest number of surveys of both children and women was Eastern and Southern Africa (64 and 58 surveys, respectively). Only four surveys were conducted in children and six surveys conducted in women in South Asia during the study period (online supplementary file 4).

Many settings had multiple surveys conducted during the study period (online supplementary file 7). Among surveys that collected data on children, $53 \%$ of settings had one survey, $27 \%$ had two surveys, $16 \%$ had three surveys and $4 \%$ had four surveys conducted. The surveys that collected data on women followed a similar pattern- $57 \%$ of settings had one survey, $18 \%$ had two surveys, $22 \%$ had three surveys and $3 \%$ had four surveys conducted. With the exception of one setting, no surveys were conducted in the same setting more than once in a given year.

\section{Anaemia in children}

In all surveys that measured haemoglobin in children 6-59 months, the median prevalence of total anaemia was $44 \%$ and median prevalence of moderate+severe anaemia was $19 \%$. Severe anaemia did not contribute significantly to the overall prevalence of total anaemia; in $88 \%$ of surveys, less than $2 \%$ of children had severe anaemia. Mild anaemia accounted for more than half of total anaemia in the majority $(73 \%)$ of surveys assessed. Moreover, approximately three in five surveys showed a prevalence of total anaemia among children 6-59 months that constitutes a problem of severe public health significance.

For all surveys, children age 6-23 months had higher prevalence of anaemia (median difference (IQR): 13\% $(10-18))$ and lower mean haemoglobin compared with the children age 24-59 months in the same survey (median difference (IQR): $-44 \mathrm{~g} / \mathrm{L}(-33$ to-55)) (not 
presented). Such that, if restricted to prevalence of moderate+severe anaemia in children 6-23 months, 31 $(16 \%)$ surveys would still have exceeded the threshold of public health significance.

South Asia had the lowest prevalence of total anaemia $(23 \%)$ and moderate+severe anaemia $(4 \%)$, but these results were based on a small number of surveys. In contrast, West and Central Africa had the highest prevalence of total anaemia $(58 \%)$ and moderate+severe anaemia $(32 \%)$; all but one of the surveys in the region, regardless of setting, indicated a problem of severe public health significance (table 1 ). The median prevalence of total and moderate+severe anaemia in the other four regions were similar (range of median total anaemia prevalence was $39 \%-44 \%$, and range of moderate+severe anaemia prevalence was 15\%-20\%). However, while little variability in the median prevalence of anaemia among children 6-59 months was observed between regions, there was substantial within region variability (figure 1 ).

There were no clear trends in the mean haemoglobin concentration or in the median prevalence of anaemia by year. Additionally, the findings were similar when these analyses were repeated using setting rather than survey as the unit of analysis (table 1, online supplemental file 1 ).

\section{Anaemia in women}

In all surveys that measured haemoglobin in women, the median prevalence of total anaemia and median prevalence of moderate+severe anaemia was $28 \%$ and $11 \%$, respectively. Eighty-seven per cent of surveys had a prevalence of severe anaemia among women less than $2 \%$; whereas, approximately a quarter of surveys reported total anaemia prevalence of $\geq 40 \%$ (table 2 ). Mild anaemia accounted for more than half of total anaemia in the majority $(76 \%)$ of surveys assessed. Generally, anaemia prevalence in women was substantially lower compared with the prevalence of anaemia among children.

Similar to the findings among children, West and Central Africa had the highest median prevalence of total anaemia and moderate+severe anaemia $(51 \%$ and $26 \%$, respectively). In West and Central Africa, $83 \%$ of surveys indicated a problem of severe public health significance. All other regions had similar levels of anaemia prevalence, with median total anaemia prevalence ranging from $18 \%$ to $33 \%$ and median moderate+severe anaemia prevalence ranging from $8 \%$ to $17 \%$. While Chad and South Asia had the lowest median prevalence of moderate+severe anaemia (8\%), Chad showed the lowest median prevalence of total anaemia $(18 \%)$. Variability of anaemia estimates within each region is displayed in figure 1.

There were no notable differences in the median prevalence of total anaemia or moderate+severe anaemia across years. Findings were similar when these analyses were repeated using setting rather than survey as the unit of analysis (table 2, online supplemental file 2).

\section{Correlations of anaemia between children and women}

Despite the fact that the prevalence of anaemia in women was much lower than in children, the prevalence of total anaemia, moderate+severe anaemia and mean haemoglobin concentration between children and women showed a highly significant, strong positive correlation $(0.80,0.76,0.79$, respectively; $\mathrm{p}<0.0001$ for all $)$. Across regions, Ethiopia and Chad showed the strongest correlation, whereas West and Central Africa showed the weakest correlation across all anaemia indicators (table 3 , figure 2). Findings were similar when these analyses were repeated using setting rather than survey as the unit of analysis (table 3 , online supplemental file 3 ).

\section{DISCUSSION}

The presented analysis provides evidence of low haemoglobin concentration and high prevalence of anaemia among populations living in refugee settings. Surveys of children aged 6-59 months had median total anaemia prevalence of $44 \%$, compared with $28 \%$ in non-pregnant women of reproductive age (15-49 years). The prevalence of total anaemia reached or exceeded $40 \%$, the global threshold for a problem of severe public health significance according to WHO classification, in $61 \%$ of surveys of children and $25 \%$ of surveys of women. ${ }^{38}$ These data therefore suggest persistent, high levels of anaemia. Ongoing measurement of anaemia in annual nutrition surveys is therefore valuable to monitor trends in prevalence as refugee settings globally progress in implementing evidence-based programmes. Targeted studies may also be valuable to characterise how ongoing displacement and implementation challenges each contribute to high prevalence.

Among children, the median prevalence of total anaemia reached or exceeded the $40 \%$ threshold in all regions of Africa, except for Chad. Anaemia prevalence was notably lower in surveys from South Asia, assessing mainly Bhutanese refugees in Nepal and Rohingya refugees in Bangladesh. The lower prevalence estimates observed in these populations may reflect long-standing multisectoral efforts to mitigate anaemia in these two countries as part of the UNHCR Anaemia Strategy; the UNHCR Anaemia Strategy started in 2008-09 and primarily targeted refugee operations in seven countries including Nepal and Bangladesh. ${ }^{30} 45$ Prevalence of anaemia was highest in West and Central Africa; nearly all settings evaluated had prevalence values suggestive of a problem of severe public health significance in both children and women. The high burden of anaemia in this region may be due to multiple factors. Previous studies have noted a larger contribution of malaria to anaemia in countries of West Africa relative to other regions. ${ }^{14647}$ Additionally, none of the countries assessed in this region were a major focus of the UNHCR Anaemia Strategy.

Consistent with previous literature, prevalence of total anaemia was higher among younger children (6-23 months) than older children (24-59 months). ${ }^{2}$ Overall, 


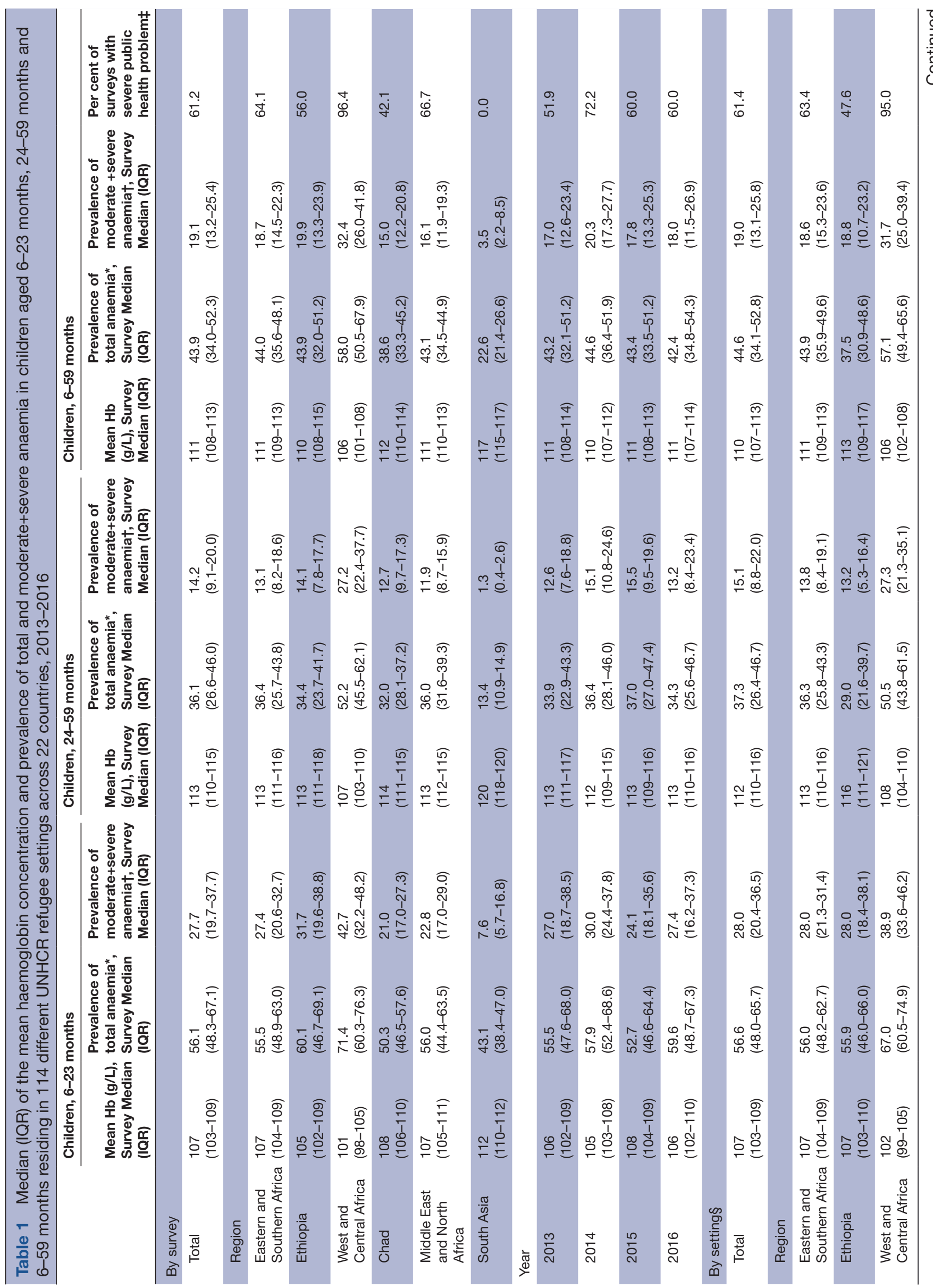




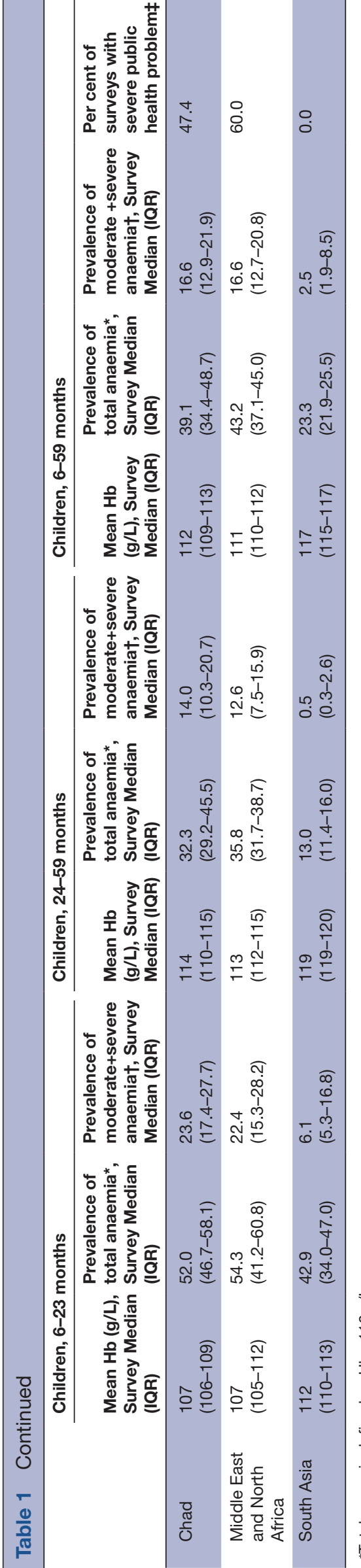

median prevalence of total anaemia was approximately $20 \%$ higher and the median estimate of mean haemoglobin was $6 \mathrm{~g} / \mathrm{L}$ lower among younger children. Prevalence of anaemia among children aged 6-59 months was much higher than among non-pregnant women of reproductive age in all regions except for South Asia. Higher prevalence of anaemia among children than nonpregnant women of reproductive age has also been documented by global estimates of anaemia in non-refugee settings. ${ }^{1}$ We observed a strong correlation between anaemia indicators measured in children and women. Haemoglobin values of children in a given population may be indicative of those for non-pregnant women, and vice versa. However, heterogeneity in the strength of these correlations exists. In some settings, such as in West and Central Africa as well as the Middle East and North Africa, the correlation is likely too low to use for prediction $(<0.6)$.

Prevalence of total anaemia as well as more critical forms of anaemia (moderate+severe anaemia) are presented given differences in clinical and public health implications. In general, severe anaemia was rare and the number of cases of mild anaemia exceeded cases of moderate+severe anaemia; however, the relative proportion of mild anaemia was highly variable and not directly proportional to total anaemia. Mild anaemia in children has been shown in previous studies to not be associated with detrimental developmental outcomes. ${ }^{48}{ }^{49}$ In addition, surveys have shown that haemoglobin concentrations in individuals of African descent are between $5 \mathrm{~g} / \mathrm{L}$ to $10 \mathrm{~g} / \mathrm{L}$ lower than those of Caucasians at any given age and in both sexes. ${ }^{50-52} \mathrm{~A}$ review by WHO of the global guidelines on thresholds used to define anaemia at the individual and population level is presently ongoing. ${ }^{53}$ Presented data suggest that a change in the global cutoffs could have implications for prioritisation in refugee settings. Further research on the implications for prioritisation and programming may be warranted should new guidance be released.

While high relative to global public health thresholds, the observed anaemia levels are consistent with those estimated for national, non-displaced populations. Systematic analysis of population representative data from 257 surveys conducted in 190 countries between 1995 and 2011 reported estimates of global prevalence of total anaemia among children (43\%) and nonpregnant women (29\%) almost identical to our data in children and women refugees $44 \%$ and $28 \%$, respectively), despite the study's inclusion of many high-income countries. ${ }^{1}$ Similar to regional patterns observed in our refugee samples, national prevalence estimates of total anaemia among children was highest in Central and West Africa. However, in contrast to our findings, South Asia was the region with the second highest estimated prevalence. Median prevalence among refugee children $(22.6 \%)$ and women $(23.3 \%)$ in the region fell outside the $95 \%$ confidence intervals estimated for the region from national surveys ( $(95 \%$ CI: 44 to 69$)$ and (95\% CI: 


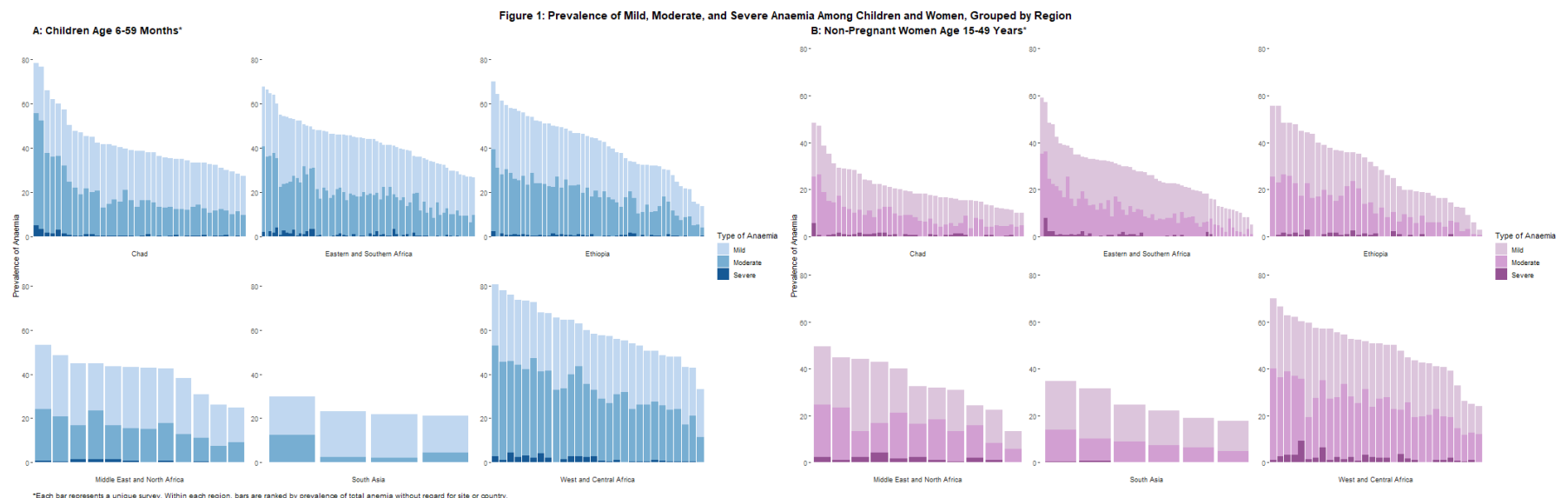

Figure 1 Prevalence of mild, moderate and severe anaemia among children and women, grouped by region.

33 to 59), respectively). ${ }^{1}$ However, our limited sample size of surveys from South Asia in the present analysis only covers two different settings, and our estimates do not adjust for sampling error, hence direct comparisons with large-scale, regional estimates should be interpreted with caution.

Table 2 Median (IQR) of the mean haemoglobin concentration and prevalence of total and moderate+severe anaemia in nonpregnant women 15-49 years of age residing in 108 different UNHCR refugee settings across 23 countries, 2013-2016

\begin{tabular}{|c|c|c|c|c|}
\hline & $\begin{array}{l}\text { Mean } \mathrm{hb}(\mathrm{g} / \mathrm{L}) \text {, } \\
\text { Survey Median } \\
\text { (IQR) }\end{array}$ & $\begin{array}{l}\text { Prevalence of total } \\
\text { anaemia, }{ }^{*} \text { Survey } \\
\text { Median (IQR) }\end{array}$ & $\begin{array}{l}\text { Prevalence of moderate } \\
\text { +severe anaemia, † Survey } \\
\text { Median (IQR) }\end{array}$ & $\begin{array}{l}\text { Per cent of surveys } \\
\text { with severe public } \\
\text { health problem } \neq\end{array}$ \\
\hline \multicolumn{5}{|l|}{ By survey } \\
\hline Total & $126(122-131)$ & $27.9(18.2-39.8)$ & $11.4(6.5-19.4)$ & 24.5 \\
\hline \multicolumn{5}{|l|}{ Region } \\
\hline Eastern and Southern Africa & $127(124-130)$ & $26.6(19.0-32.8)$ & $9.1(6.2-14.7)$ & 8.6 \\
\hline Ethiopia & $125(122-130)$ & $29.8(18.4-38.8)$ & $12.1(5.9-19.8)$ & 24.3 \\
\hline West and Central Africa & $118(116-121)$ & $50.7(42.1-57.1)$ & $25.5(19.5-31.3)$ & 83.3 \\
\hline Chad & $132(128-133)$ & $18.2(15.2-24.1)$ & $8.2(4.9-11.4)$ & 4.8 \\
\hline Middle East and North Africa & $123(120-126)$ & $32.6(24.3-44.1)$ & $16.5(13.2-21.1)$ & 36.4 \\
\hline South Asia & $127(125-129)$ & $23.3(19.0-31.6)$ & $8.1(6.3-10.1)$ & 0.0 \\
\hline \multicolumn{5}{|l|}{ Year } \\
\hline 2013 & $127(122-131)$ & $27.8(17.7-39.7)$ & $10.4(6.3-21.4)$ & 24.0 \\
\hline 2014 & $126(122-129)$ & $26.5(22.0-38.8)$ & $11.4(8.1-18.9)$ & 23.1 \\
\hline 2015 & $125(121-132)$ & $31.1(16.1-42.1)$ & $12.1(5.9-19.4)$ & 26.2 \\
\hline 2016 & $128(122-132)$ & $24.3(16.6-39.2)$ & $10.4(5.3-17.2)$ & 23.5 \\
\hline \multicolumn{5}{|l|}{ By setting§ } \\
\hline Total & $126(122-130)$ & $29.3(18.1-39.1)$ & $12.3(6.6-19.0)$ & 24.1 \\
\hline \multicolumn{5}{|l|}{ Region } \\
\hline Eastern and Southern Africa & $127(124-130)$ & $26.6(18.1-32.8)$ & $9.3(6.2-15.4)$ & 8.1 \\
\hline Ethiopia & $130(123-135)$ & $18.9(13.4-33.6)$ & $7.5(5.6-15.0)$ & 15.0 \\
\hline West and Central Africa & $119(116-122)$ & $51.2(40.2-57.1)$ & $24.0(19.4-31.5)$ & 75.0 \\
\hline Chad & $130(125-133)$ & $20.9(15.4-31.0)$ & $10.1(5.4-14.3)$ & 10.5 \\
\hline Middle East and North Africa & $123(120-123)$ & $32.6(31.9-42.9)$ & $16.5(13.4-18.3)$ & 33.3 \\
\hline South Asia & $127(126-128)$ & $24.7(23.3-26.8)$ & $8.1(7.4-10.1)$ & 0.0 \\
\hline
\end{tabular}

${ }^{*}$ Total anaemia defined as $\mathrm{Hb}<120 \mathrm{~g} / \mathrm{L}$.

†Moderate+severe anaemia defined as $\mathrm{Hb}<100 \mathrm{~g} / \mathrm{L}$.

$\ddagger$ Severe public health problem defined as prevalence of total anaemia $\geq 40 \%$.

$\S M e d i a n$ value for each indicator across all surveys conducted in a given setting (refugee camp or non-camp site).

$\mathrm{Hb}$, haemoglobin; UNHCR, United Nations High Commissioner for Refugees. 
Table 3 Correlations of the mean haemoglobin concentration and prevalence of total anaemia and moderate+severe anaemia between children aged 6-59 months and non-pregnant women aged 15 to 49 years residing in 100 different UNHCR refugee settings across 21 countries, 2013-2016

\begin{tabular}{|c|c|c|c|}
\hline & $\begin{array}{l}\text { Correlation of } \\
\text { mean } \mathrm{Hb}(\mathrm{g} / \mathrm{L})\end{array}$ & $\begin{array}{l}\text { Correlation of prevalence } \\
\text { of total anaemia* }\end{array}$ & $\begin{array}{l}\text { Correlation of prevalence of } \\
\text { moderate+severe anaemia }\end{array}$ \\
\hline \multicolumn{4}{|l|}{ By survey } \\
\hline Overall correlation & 0.79 & 0.80 & 0.76 \\
\hline \multicolumn{4}{|l|}{ Region } \\
\hline Eastern and Southern Africa & 0.72 & 0.75 & 0.72 \\
\hline Ethiopia & 0.88 & 0.86 & 0.76 \\
\hline West and Central Africa & 0.59 & 0.58 & 0.53 \\
\hline Chad & 0.85 & 0.84 & 0.79 \\
\hline Middle East and North Africa & 0.73 & 0.62 & 0.57 \\
\hline \multicolumn{4}{|l|}{ By settingf } \\
\hline Overall correlation & 0.79 & 0.82 & 0.77 \\
\hline \multicolumn{4}{|l|}{ Region } \\
\hline Eastern and Southern Africa & 0.75 & 0.79 & 0.73 \\
\hline Ethiopia & 0.94 & 0.94 & 0.86 \\
\hline West and Central Africa & 0.57 & 0.60 & 0.57 \\
\hline Chad & 0.86 & 0.91 & 0.86 \\
\hline Middle East and North Africa & 0.76 & 0.64 & 0.68 \\
\hline
\end{tabular}

*Total anaemia in women and children defined as $\mathrm{Hb}<120 \mathrm{~g} / \mathrm{L}$ and $\mathrm{Hb}<110 \mathrm{~g} / \mathrm{L}$, respectively.

†Moderate+severe anaemia defined in women and children as $\mathrm{Hb}<110 \mathrm{~g} / \mathrm{L}$ and $\mathrm{Hb}<100 \mathrm{~g} / \mathrm{L}$, respectively.

$\ddagger$ Median value for each indicator across all surveys conducted in a given setting (refugee camp or non-camp site).

$\mathrm{Hb}$, hemoglobin; UNHCR, United Nations High Commissioner for Refugees.

Our study is subject to several limitations. First, as emergency surveys, SENS surveys measure only haemoglobin; no other anaemia-related biochemical markers (ie, iron, folate, vitamin A, or vitamin B12 status), genetic conditions (such as sickle cell anaemia or thalassemia), or indicators of inflammation were measured. As such, presented estimates of anaemia prevalence are not adjusted for inflammation. Subclinical inflammation increases blood haemoglobin, resulting in an underestimate of anaemia prevalence. ${ }^{254}$ For the reasons above, we cannot differentiate between general anaemia and IDA. Using the Global Burden of Diseases, Injuries, and Risk Factors Study 2010, researchers have modelled the proportion of anaemia attributed to iron deficiency to approximate $50 \%$ of total anaemia. ${ }^{3}$ Subsequent studies have suggested that the proportion of anaemic children with iron deficiency is higher in countries with high infection burden $(58 \%)$, and lower in Africa (32\%) and South-East Asia (41\%). ${ }^{255}$ Second, refugee settings experience considerable migration, limiting interpretability of annual trends for a given setting or country. UNHCR estimates that the global population of refugees increased annually during the study period. ${ }^{56}$ However, the presented analysis provides some evidence that prevalence of anaemia in both target

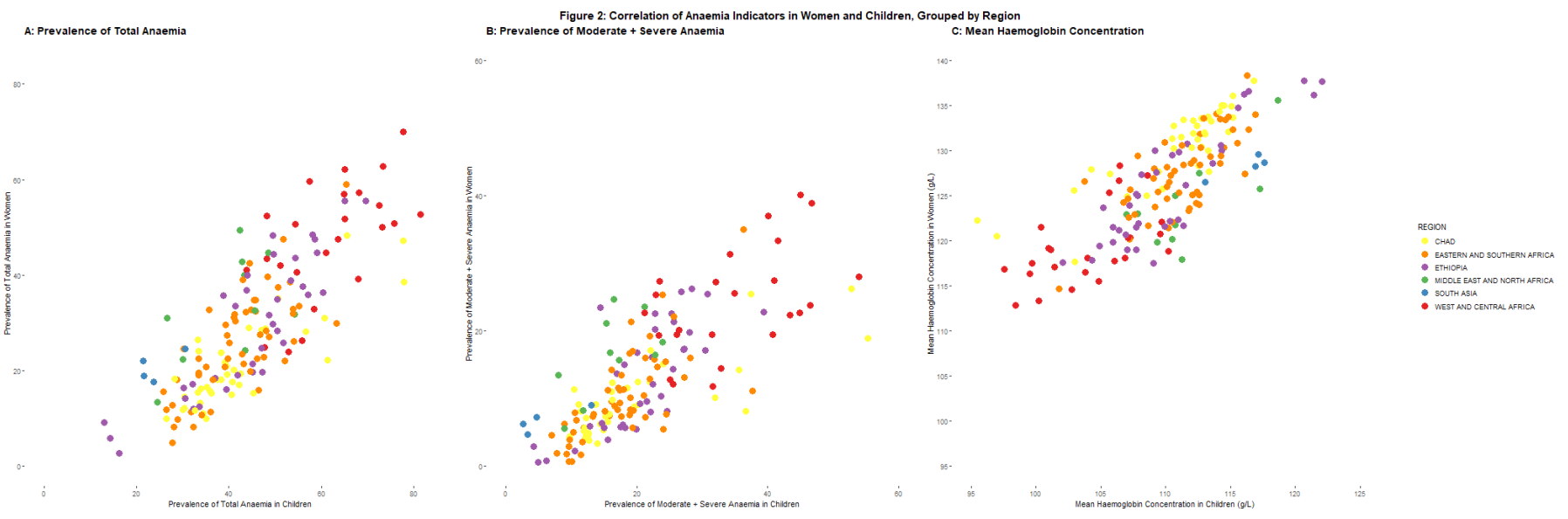

Figure 2 Correlation of anaemia indicators in women and children, grouped by region. 
groups remained largely unchanged throughout 20132016. Finally, details on health and nutrition programme availability and coverage at the time of the assessments were not systematically recorded or measured in the survey reports, limiting impact assessments of ongoing interventions.

\section{CONCLUSION}

In summary, this secondary analysis represents the first multi-year global analysis characterising the burden of anaemia among refugees. The study confirms the importance and relevance of continuing to measure haemoglobin in nutrition surveys among refugee populations. While the prevalence of anaemia is high in children and women, it aligns with that observed in the general population and demonstrates the need to focus on children under 2 years of age who bear the highest burden. ${ }^{1}$ Continued multisectoral approaches are key to reducing a condition of complex aetiologies, particularly in geographic regions with a greater burden such as the West and Central Africa region. Further research is needed to find ways to best assess the programmatic impact of anaemia reduction activities among refugee populations.

Acknowledgements We acknowledge the important contributions of Erin Hulland, Curtis Blanton, and Rebecca Wee in preparation of the data.

Contributors All authors contributed equally to this study. EL, OB, CW, MT designed the study. EL, OB, CW, MT collected the data. AK, VL, EL, OB, analysed and interpreted the data. AK, VL, EL and OB drafted the manuscript. CW, MT critically revised the manuscript for important intellectual content. All authors read and approved the final manuscript. $\mathrm{OB}$ is a guarantor. All authors have read and approved the manuscript, have full access to all of the data, and take responsibility for the integrity of the data and the accuracy of the data analysis.

Funding The authors have not declared a specific grant for this research from any funding agency in the public, commercial or not-for-profit sectors.

\section{Competing interests None declared.}

Patient consent for publication Not required.

Provenance and peer review Not commissioned; externally peer reviewed.

Data availability statement The data that support the findings of this study are available from the United Nations High Commissioner for Refugees but restrictions apply to the availability of these data, which were used under license for the current study, and so are not publicly available. Data are however available from the authors upon reasonable request and with permission of the United Nations High Commissioner for Refugees.

Open access This is an open access article distributed in accordance with the Creative Commons Attribution Non Commercial (CC BY-NC 4.0) license, which permits others to distribute, remix, adapt, build upon this work non-commercially, and license their derivative works on different terms, provided the original work is properly cited, appropriate credit is given, any changes made indicated, and the use is non-commercial. See: http://creativecommons.org/licenses/by-nc/4.0/.

\section{ORCID iD}

Eva Leidman http://orcid.org/0000-0002-4191-5931

\section{REFERENCES}

1 Stevens GA, Finucane MM, De-Regil LM, et al. Global, regional, and national trends in haemoglobin concentration and prevalence of total and severe anaemia in children and pregnant and non-pregnant women for 1995-2011: a systematic analysis of populationrepresentative data. The Lancet Global Health 2013;1:e16-25.

2 Engle-Stone R, Aaron GJ, Huang J, et al. Predictors of anemia in preschool children: biomarkers reflecting inflammation and nutritional determinants of anemia (BRINDA) project. Am J Clin Nutr 2017:106:402s-15

3 Kassebaum NJ, Jasrasaria R, Naghavi M, et al. A systematic analysis of global anemia burden from 1990 to 2010. Blood 2014; $123: 615-24$

4 Petry N, Olofin I, Hurrell R, et al. The proportion of anemia associated with iron deficiency in low, medium, and high human development index countries: a systematic analysis of national surveys. Nutrients 2016;8:693.

5 Shafir T, Angulo-Barroso R, Jing Y, et al. Iron deficiency and infant motor development. Early Hum Dev 2008;84:479-85.

6 Carter RC, Jacobson JL, Burden MJ, et al. Iron deficiency anemia and cognitive function in infancy. Pediatrics 2010;126:e427-34.

7 Chang S, Wang L, Wang Y, et al. Iron-Deficiency anemia in infancy and social emotional development in preschool-aged Chinese children. Pediatrics 2011;127:e927-33.

8 Grantham-McGregor S, Ani C. A review of studies on the effect of iron deficiency on cognitive development in children. $J$ Nutr 2001;131:649S-68. discussion 66S-68S.

9 Lozoff B, Beard J, Connor J, et al. Long-Lasting neural and behavioral effects of iron deficiency in infancy. Nutr Rev 2006;64:34-43. discussion S72-915.

10 Brabin BJ, Hakimi M, Pelletier D. An analysis of anemia and pregnancy-related maternal mortality. J Nutr 2001;131:604S-15. discussion 14S-15S.

11 Khan KS, Wojdyla D, Say L, et al. Who analysis of causes of maternal death: a systematic review. The Lancet 2006;367:1066-74.

12 Nair M, Churchill D, Robinson S, et al. Association between maternal haemoglobin and stillbirth: a cohort study among a multi-ethnic population in England. Br J Haematol 2017;179:829-37.

13 Kozuki N, Lee AC, Katz J, et al. Moderate to severe, but not mild, maternal anemia is associated with increased risk of small-forgestational-age outcomes. J Nutr 2012;142:358-62.

14 Steer PJ. Maternal hemoglobin concentration and birth weight. Am J Clin Nutr 2000;71:1285S-7.

15 UNICEF. The State of the World's Children 1998. New York, 1998. Available: https://www.unicef.org/sowc98/sowc98.pdf [Accessed March 15 2019].

16 Peña M, Bacallao J. Malnutrition and poverty. Annu Rev Nutr 2002;22:241-53.

17 Tanumihardjo SA, Anderson C, Kaufer-Horwitz M, et al. Poverty, obesity, and malnutrition: an international perspective recognizing the paradox. J Am Diet Assoc 2007;107:1966-72.

18 Prendergast AJ, Kelly P. Interactions between intestinal pathogens, enteropathy and malnutrition in developing countries. Curr Opin Infect Dis 2016;29:229-36.

19 Solomons NW. Malnutrition and infection: an update. Br J Nutr 2007;98:S5-10.

20 Ahmed JA, Katz MA, Auko E, et al. Epidemiology of respiratory viral infections in two long-term refugee camps in Kenya, 2007-2010. BMC Infect Dis 2012;12:7.

21 Connolly MA, Gayer M, Ryan MJ, et al. Communicable diseases in complex emergencies: impact and challenges. The Lancet 2004;364:1974-83

22 Milton A, Rahman M, Hussain S, et al. Trapped in Statelessness: Rohingya refugees in Bangladesh. Int J Environ Res Public Health 2017;14:942.

23 Mason JB. Lessons on nutrition of displaced people. J Nutr 2002:132:2096S-103.

24 Nutrition Service of the World Food Program. Nutrition in emergencies: WFP experiences and challenges. Food Nutr Bull 2006;27:57-66.

25 Henry CJK, Seaman J. The micronutrient fortification of refugee rations to prevent nutritional deficiencies in refugee diets. $J$ Refug Stud 1992:5:359-67.

26 Dye TD. Contemporary prevalence and prevention of micronutrient deficiencies in refugee settings worldwide. J Refug Stud 2007:20:108-19.

27 Haidar J. Common micronutrient deficiencies among food aid beneficiaries: evidence from refugees in Ethiopia. Ethiopian $\mathrm{J}$ Health Develop 2011;25:222-9.

28 Seal AJ, Creeke PI, Mirghani Z, et al. Iron and vitamin A deficiency in long-term African refugees. J Nutr 2005;135:808-13.

29 Bilukha OO, Jayasekaran D, Burton A, et al. Nutritional status of women and child refugees from Syria-Jordan, April-May 2014. MMWR morbidity and mortality Weekly report 2014;63:638-9.

30 UNHCR. Strategic plan for anaemia prevention, control and reduction (2008-2010), 2008. Available: https://www.unhcr.org/ protection/health/4b8e854d9/unhcr-strategic-plan-anaemiaprevention-control-reduction-reducing-global.html [Accessed March 18 2019]. 
31 UNHCR. Standardised expanded nutrition survey, version 2, 2013. Available: http://sens.unhcr.org/introduction/ [Accessed March 20 2019].

32 UNHCR. UNHCR standardised expanded nutrition survey (senS) guidelines for refugee populations, module 2: anaemia. version 2 ED 2013.

33 UNHCR. UNHCR standardised expanded nutrition survey (senS) guidelines for refugee populations, Pre-Module: survey steps and sampling, 2013. Available: http://sens.unhcr.org/wp-content/ uploads/2015/03/UNHCR_SENS_Pre-Module_v2.pdf [Accessed March 20 2019].

34 SMART, Action Against Hunger Canada, Technical Advisory Group. Standardized monitoring and assessment for relief and transitions, manual 2.0, 2017. Available: https://smartmethodology.org/wpcontent/uploads/2018/02/SMART-Manual-2.0_Final_January-9th2017-for-merge-3.pdf [Accessed March 20 2019].

35 HemoCue America. HemoCue $\AA$ Hb 301 system, 2019. Available: https://www.hemocue.us/en-us/solutions/hematology/hemocue-hb301-system [Accessed March 20 2019].

$36 \mathrm{WHO}$. Haemoglobin concentrations for the diagnosis of anaemia and assessment of severity. World Health Organization, 2011.

37 WHO. Unicef, UNU. iron deficiency anaemia: assessment, prevention, and control. A guide for programme managers. Geneva: World Health Organization, 2001.

$38 \mathrm{WHO}$. The management of nutrition in major emergencies. Geneva: World Health Organization, 2000.

39 Sullivan KM, Mei Z, Grummer-Strawn L, et al. Haemoglobin adjustments to define anaemia. Tropical Medicine International Health 2008;13:1267-71.

40 SAS Institute. Sas software version 9.3 for windows. Cary, NC: SAS Institute Inc, 2014.

41 SAS Institute. Sas software version 9.4 for windows. Cary, NC: SAS Institute Inc, 2014.

42 Rstudio Team. RStudio: integrated development for R. Boston, MA: RStudio, Inc, 2015.

43 Wickham H. Reshaping Data with the reshape Package. J Stat Softw 2007;21.

44 Wickham H. ggplot2: elegant graphics for data analysis. New York: Springer, 2009.
45 UNHCR. Global strategy implementation report, 2016. Available: https://www.unhcr.org/58d524b17.pdf [Accessed March 18 2019].

46 Korenromp EL, Armstrong-Schellenberg JRM, Williams BG, et al. Impact of malaria control on childhood anaemia in Africa -- a quantitative review. Trop Med Int Health 2004;9:1050-65.

47 Soares Magalhães RJ, Clements ACA. Mapping the risk of anaemia in preschool-age children: the contribution of malnutrition, malaria, and helminth infections in West Africa. PLoS Med 2011;8:e1000438-e.

48 Sherriff A, Emond A. Should infants be screened for anaemia? A prospective study investigating the relation between haemoglobin at 8, 12, and 18 months and development at 18 months. Arch Dis Child 2001;84:480-5.

49 Lozoff B, Brittenham GM, Wolf AW, et al. Iron deficiency anemia and iron therapy effects on infant developmental test performance. Pediatrics 1987;79:981-95.

50 Dallman PR, Barr GD, Allen CM, et al. Hemoglobin concentration in white, black, and Oriental children: is there a need for separate criteria in screening for anemia? Am J Clin Nutr 1978;31:377-80.

51 Garn SM, Ryan AS, Owen GM, et al. Income matched blackwhite hemoglobin differences after correction for low transferrin saturations. Am J Clin Nutr 1981;34:1645-7.

52 Johnson-Spear MA, Yip R. Hemoglobin difference between black and white women with comparable iron status: justification for racespecific anemia criteria. Am J Clin Nutr 1994;60:117-21.

53 World Health Organization. Technical meeting: use and interpretation of haemoglobin concentrations for assessing anaemia status in individuals and populations. 2017. Geneva Switzerland Available: https://www.who.int/nutrition/events/2017-meetinghaemoglobin-concentrations-anaemia-29novto1dec/en/ [Accessed May 14 2019].

54 Grant FKE, Suchdev PS, Flores-Ayala R, et al. Correcting for inflammation changes estimates of iron deficiency among rural Kenyan preschool children. J Nutr 2012;142:105-11.

55 WHO. The global prevalence of anaemia in 2011. Geneva (Switzerland: World Health Organization, 2015.

56 UNHCR. Global trends forced displacement in 2017: United nations high commissioner for refugees, 2018. Available: https://www.unhcr. org/5b27be547.pdf [Accessed March 29 2019]. 